\title{
Fertility histories and chronic conditions later in life in Europe
}

\author{
Maria Sironi ${ }^{1}[0$ \\ Published online: 29 November 2018 \\ (c) The Author(s) 2018
}

\begin{abstract}
Understanding the association between fertility histories and health later in life is necessary in the context of ageing societies. Past literature has generally found a U-shaped relationship between parity, age at first birth, and several health-related outcomes. However, these findings differed to some extent depending on the country under analysis and on the measures of health considered. As such, using wave 3 (2008-2009) and 5 (2013) of the Survey of Health, Ageing and Retirement in Europe (SHARE), this work aimed to answer the question: "Are fertility histories associated with the presence of chronic conditions later in life in Europe?" The analysis included 11 European countries and compared results using two different measures of chronic conditions: self-reported chronic or long-term illness and chronic diseases diagnosed by a doctor. Results showed that age at first birth is more relevant than parity for health outcomes at older ages. Moreover, in socio-democratic and continental countries, the association between fertility and chronic conditions-in particular between age at first birth and long-term illnesses-is statistically significant among women, but not among men. Finally, the association between fertility history and health was similar when using self-reported measures and chronic diseases diagnosed by a doctor.
\end{abstract}

Keywords Fertility $\cdot$ Health $\cdot$ Ageing $\cdot$ Europe $\cdot$ SHARE $\cdot$ Chronic diseases

\section{Introduction}

It is well known that life expectancy in developed countries has increased for decades, and this pattern is likely to continue thanks to medical innovations. Over the same period of time, fertility rates have decreased substantially. Given the decrease in mortality rates and fertility rates, the age structure of industrialized societies has changed and shifted towards an older population (European Commission 2014), and health inequalities among older people have become starker (Marmot 2005). An overview of health conditions among older adults in Europe showed that inequalities in self-reported health and disability persist in old age (Huisman et al. 2003). Consequently, heightened morbidity and longer periods spent with a lower quality of life have become serious threats for larger segments of the population. Chronic diseases - in particular cancer and diseases of the

Responsible editor: Susanne Iwarsson.

Maria Sironi

m.sironi@ucl.ac.uk

1 Department of Social Science, University College London, 20 Bedford Way, London WC1H 0AL, UK circulatory system - are the main cause of death and of disability in European countries, especially among older adults (Eurostat 2016). The rise in chronic conditions is reflected in longer life spans with the disease, due to earlier and more accurate diagnosis (Kuh and Shlomo 2004; Kuh et al. 2013). Hence, it is important to focus on this outcome and identify major risk factors to better understand the ageing process.

Several life course theories hypothesize that health in adulthood is the result of early life conditions and even critical moments in utero or early infancy (Barker 1997, 2004; Roseboom et al. 2001; Barker et al. 2002) and that health among older people is driven by a continuous and cumulative process that develops over the life course (Halfon and Hochstein 2002). According to these models, health at a specific point in time is determined by all of the events that happened previously and the dynamic interaction between them. Therefore, it is important to take into account key events across the life course to fully understand health conditions among older people (Kuh and Shlomo 2004). Among these events and because of the decline in fertility rates, childbearing has attracted a lot of attention in the demographic, epidemiological, and ageing literatures. The consequences of fertility histories on mortality and health have been widely investigated. Past research has shown the existence of a 
relationship between parity and age at first birth and mortality (Doblhammer 2000; Grundy and Kravdal 2007, 2010; Grundy and Tomassini 2006; Hinkula et al. 2005; Hurt et al. 2006; Jaffe et al. 2009, 2011; Tamakoshi et al. 2010). More recently, studies have also found an association between fertility and physical and mental health outcomes in middle and old age, such as self-rated health, chronic conditions, and depression (Buber and Engelhardt 2008; Grundy and Tomassini 2005; Grundy and Foverskov 2016; Grundy and Holt 2000; Gunes 2016; Hank 2010; Hanson et al. 2015; Henretta 2007; O' Flaherty et al. 2016; Pirkle et al. 2014; Read et al. 2011; Williams et al. 2011).

However, most of the previous studies have either focused on a single country or on the comparison between two countries or small groups of countries. Therefore, it is necessary to extend cross-national comparisons given all of the factors (discussed below) that can make the association between fertility and health different in various contexts. Existing literature has primarily used self-reported measures of health and has not compared these associations across different measures of the same health conditions. Thus, to overcome these gaps in the literature and to understand the determinants of ageing patterns of older adults, this study included several European countries and investigated the role of fertility histories in shaping health later in life. In particular, I analysed chronic conditions, using both strictly self-reported measures of long-term illness and self-reported doctor diagnoses.

\section{Literature review and theoretical background}

As previous studies have shown, there are several mechanisms through which fertility can affect health and mortality (Goisis and Sigle-Rushton 2014; Grundy and Tomassini 2005). The primary direct mechanism is the effect of pregnancy on a woman's body. It can cause immediate disadvantages, such as post-partum depression and weight gain, and other consequences due to physiological stress. However, childbirth can also cause a rise in a woman's stress resilience and it can benefit medical care and social integration. The mother's age, her marital and employment status, the number of children already born, and other socio-economic characteristics affect these consequences. Breastfeeding has been found to have an impact on maternal health (Heinig and Dewey 1997), such as preventing incidence of diabetes, heart disease, and breast cancer. There are also indirect mechanisms by which fertility can affect health, like the social status associated with being a parent, the social support, and the intergenerational transfers implied by parenthood. These social mechanisms affect both men and women and can have both positive (e.g. social support) and negative effects (e.g. economic strain, stress). In particular, the negative effects are likely to be stronger for young parents (e.g. teenage parents), who have less resources to cope with stress and financial difficulties (Falci et al. 2010). The implications of these social mechanisms are likely to persist in older age, when social support and social networks are key factors for healthy ageing.

Previous literature has found that the most consistent result is a U-shaped relationship between parity and mortality/health, with individuals having two or three children having the lowest mortality risk and best health outcomes (Grundy 2009; Kravdal et al. 2012; Spence and Eberstein 2009). Teenage childbearing, short birth intervals and the death of a child have negative consequences on health (Grundy and Read 2015; Hank 2010; Henretta 2007; Read et al. 2011). Late age at childbearing is associated with better physical health but worse mental health later in life (Spence 2008; Read and Grundy 2011). All these associations are partially mediated by marital history, socio-economic factors, and health behaviours.

However, results differ to some extent depending on the country and on the measures of health that are considered. The negative impact of childlessness, high parities, and early age at first birth seems to be stronger for women in Great Britain and Germany (Grundy and Tomassini 2005, 2006; Hank 2010), while it is stronger among men in Egypt and Australia (Engelman et al. 2010; O' Flaherty et al. 2016). The relationship between fertility and health is mitigated by socio-economic factors in the USA, yet that is not the case in the UK (Henretta et al. 2008).

The fact that fertility histories affect the health of men and women in different ways across varying contexts and that socio-economic and lifestyle variables play a more important role in some locations than in others suggests that the mechanisms and the channels through which this association between fertility and health works are not universal. There are several aspects to consider that might contribute to crossnational variations. Firstly, historical contexts might influence individual fertility behaviours and create differences across countries. For example, the Great Depression hit some countries harder than others (e.g. Italy and the Netherlands more than Spain) and later than others (e.g. France). Thus, it is necessary to consider the long-term effects of the event on affected economies and on demographic behaviours, including fertility. Another example is World War II and the resulting Baby Boom in particular countries, such as France and Germany. Secondly, fertility-related welfare transfers, such as childcare provisions and gender equality policies, can mitigate the economic burden and stress associated with childbearing, especially for vulnerable groups (e.g. young parents or large families). Consequently, in Northern Europe, where welfare provisions are generous, it is plausible to expect less negative associations between fertility events and health later in life. Thirdly, cultural aspects 
such as gender roles and gender norms could explain crossnational gender differences in the association between fertility history and health. The contrasts between gender equality at the institutional level (e.g. education and labour market) and at the individual level (e.g. division of housework) have been considered as key factors for fertility decisions (McDonald 2000a, b, 2006; Esping-Andersen and Billari 2015), and it can impact the way in which fertility trajectories affect health. Hence, Southern and Eastern European countries, with low levels of gender equality, might show lower levels of fertility and stronger associations between fertility and chronic conditions among women than among men. Additionally, there are variations in the national health care systems, and this can influence the way in which individuals access and utilize health services. Finally, the selection into specific fertility pathways (e.g. early first birth or high parity) might vary across countries.

Moreover, previous studies differ in the way in which health is measured, and this may be the reason why findings are not always consistent. Recent literature using objective measures (biomarkers in particular) (Grundy and Read 2015; Hardy et al. 2007; Lacey et al. 2016) has shown that number of children is not significantly associated with health later in life, or that the association disappears after controlling for health behaviours and lifestyle. Hence, it is relevant to compare different measures of the same health conditions to have a more comprehensive picture. It is important to note that the variation in fertility rates across Europe has decreased over time. Therefore, among younger cohorts, the association between parity and health might be less strong than in the past or less clear-cut than in societies with higher levels of fertility.

Using wave 3 (2008-2009) and 5 (2013) of the Survey of Health, Ageing and Retirement in Europe (SHARE), this study aimed to answer the question, "Are fertility histories associated with the presence of chronic conditions later in life in Europe?" Furthermore, I looked at differences in this association across 11 European countries and compared results using two different measures of chronic conditions.

\section{Data and methods}

SHARE is a cross-national panel data study, which started in 2004 and involved interviews with individuals aged 50 and above in 21 European countries. SHARE is the first survey in Europe to focus specifically on ageing and to look at health conditions of a growing group of the population. For the purpose of this analysis, only wave 3 (2008-2009) and wave 5 (2013) were used. Wave 3, also known as SHARELIFE, focuses on people's life histories and contains information on several areas, such as fertility and partnership histories, housing and work histories, childhood health, and early life conditions. Wave 5 includes important variables on individuals' health. The target population ${ }^{1}$ of individuals in wave 5 is defined as "persons born in 1962 or earlier, and persons who are a spouse/partner of a person born in 1962 or earlier" (Malter and Börsch-Supan 2015). The survey sample design is different across countries (Börsch-Supan and Jürges 2005), and the response and retention rates vary by wave and country ${ }^{2}$ (Börsch-Supan 2018).

The analyses were restricted to respondents who were interviewed both in wave 3 and in wave 5 , and who were 50 years old or older in $2013(15,116)$. Twenty-five individuals were excluded because they did not answer the chronic conditions questions in wave 5 , and 382 were excluded because they did not have information on the other variables included in the analysis. The final sample consisted of 8289 women and 6420 men, from 11 European countries: Austria, Germany, Sweden, the Netherlands, Spain, Italy, France, Denmark, Switzerland, Belgium, and Czech Republic. ${ }^{3}$

\section{Measures of health}

Three different dependent variables from wave 5 were used in this analysis regarding chronic conditions. The first variable was self-reported long-term illness. Respondents were asked the question, "Some people suffer from chronic or long-term health problems. By chronic or long-term, we mean it has troubled you over a period of time or is likely to affect you over a period of time. Do you have any such health problems, illness, disability or infirmity?" (yes or no). The other two variables were measures of chronic conditions as diagnosed by a doctor. Individuals in the sample were shown a card with a list of conditions, ${ }^{4}$ and they answered

\footnotetext{
1 SHARE data are anonymized, and informed consent was obtained from all individual participants included in the survey.

${ }^{2}$ For more details, see Chapter 8 "Fieldwork monitoring and survey participation 101 in the fifth wave of SHARE" in Malter and BörschSupan (Eds.) (2015). SHARE Wave 5: Innovations \& Methodology. Munich: MEA, Max Planck Institute for Social Law and Social Policy.

3 These are the abbreviations used for the countries in the sample: $\mathrm{AT}=$ Austria, $\mathrm{DE}=$ Germany, $\mathrm{SE}=$ Sweden, $\mathrm{NL}=$ the Netherlands, $\mathrm{ES}=$ Spain, $\mathrm{IT}=$ Italy, $\mathrm{FR}=$ France, $\mathrm{DK}=$ Denmark, $\mathrm{CH}=$ Switzer land, $\mathrm{BE}=$ Belgium, $\mathrm{CZ}=$ Czech Republic.

4 The list of conditions on the card showed to the respondents includes the following: a heart attack including myocardial infarction or coronary thrombosis or any other heart problem including congestive heart failure; high blood pressure or hypertension; high blood cholesterol; a stroke or cerebral vascular disease; diabetes or high blood sugar; chronic lung disease such as chronic bronchitis or emphysema; cancer or malignant tumour, including leukaemia or lymphoma, but excluding minor skin cancers; stomach or duodenal ulcer, peptic ulcer; Parkinson disease; cataracts; hip fracture; other fractures; Alzheimer's disease, dementia, organic brain syndrome, senility or any other serious memory impairment; other affective or emotional disorders, including anxiety, nervous or psychiatric prob-
} 
the question, "Has a doctor ever told you that you had/ Do you currently have any of the conditions on this card? Please tell me the number or numbers of the conditions." The answer to this question was used to build (a) a dichotomous variable equal to 1 if the respondent was diagnosed with at least one chronic condition, and 0 otherwise, and (b) a variable corresponding to the number of diagnosed chronic conditions. Although these two variables are not strictly objective measures, as the respondent reports them they provide a more comprehensive picture together with the self-reported long-term illness variable, given that they imply a doctor diagnosis (and so access and active use of health care services).

\section{Measures of fertility}

Several independent variables representing the fertility trajectory were used in the analysis: number of children, age at first birth and age at last birth, short birth interval (equal to 1 if the distance between two births is less than 2 years), long birth interval (equal to 1 if the distance between two births is more than 5 years), and experiencing the death of a child (equal to 1 if the responded reported the death of a child). The use of several variables on fertility offered a more detailed picture than just using parity, or age at first birth, and could help identify other aspects of childbearing that can be important risk factors for later health.

\section{Control variables}

The control variables included in the analysis were age at interview at wave 5 , level of education, ${ }^{5}$ if retired from work at wave 5, partnership status, ${ }^{6}$ the number of marriages, if ever cohabited with a partner, early life conditions, ${ }^{7}$ and childhood health $^{8}$ included in wave 3 . Control variables were identified through the past literature and found to be associated with health and/or fertility histories. For example, childhood health (Barker 1997; Case et al. 2005) and early life conditions (Campbell et al. 2014; Cohen et al. 2010; Duncan

\footnotetext{
Footnote 4 (continued)

lems; rheumatoid arthritis; osteoarthritis, or other rheumatism; none; other conditions, not yet mentioned.

${ }^{5}$ No education, primary or lower secondary, upper secondary, and tertiary education according to the ISCED scale.

${ }^{6}$ Single, married or cohabiting, divorced or separated, and widow (at wave 5).

7 Parents' education (highest between mother and father), if living with both biological parents when 10, the number of people per bedroom when 10, books in the household, housing conditions.

${ }^{8}$ Self-reported health, had vaccines, had a health care source, missing school for a month or more due to health problems, being hospitalized for a month or more.
}

et al. 2010) have shown a strong correlation with adult health. Moreover, education, occupation, and partnership histories could influence the fertility trajectory, given that the number of children and the timing of childbirth vary with different levels of SES (Clark and Cummins 2009; Clark and Hamilton 2006; Dribe et al. 2014; Skirbekk 2008) and are mediated by the presence of a partner (O’Leary et al. 2010).

\section{Statistical analysis}

Because of the previous findings in the literature showing a differing impact of childbearing on men and women, all of the analyses were performed separately by gender. Following some descriptive statistics ${ }^{9}$ of the variables used in the analysis by gender and by country, multivariate regression models were run to estimate the association between the different fertility variables and chronic conditions. ${ }^{10}$

First, to have a general picture of the associations in Europe, an analysis was performed on all the countries together. Self-reported long-term illness was looked at by running six logistic models, each one focusing on a different fertility characteristic: parity, age at first and last birth, short and long birth interval, and death of a child. Each specification included the control variables, the number of children, and country dummies. Then, the presence of diagnosed chronic diseases (also in this case using six logistic regression models) was looked at, and at the number of chronic diseases using negative binomial regression models.

Secondly, the models were run for self-reported long-term illness and for the presence of diagnosed chronic diseases by country. Comparing the results across different measures of chronic conditions allowed an evaluation of whether the results were influenced by the type of measure used. The analyses were performed using STATA, reporting different levels of statistical significance of the coefficients $\left({ }^{*} p<0.10\right.$, $* * p<0.05, * * * p<0.01)$.

\section{Results}

\section{Descriptive results}

Tables 1 and 2 show heterogeneity in the prevalence of chronic conditions across European countries. The prevalence of self-reported long-term illnesses was lowest in

\footnotetext{
${ }^{9}$ Descriptive statistics are weighted using calibrated weights to take into account attrition, non-response rate, and sample differences across countries.

${ }^{10}$ Given the large number of regression models in the analysis (due to different outcomes and different fertility measures), no bivariate associations are reported in "Results" section, but are available upon request.
} 
Table 1 Sociodemographic characteristics and healthdescriptive statistics-women

\begin{tabular}{|c|c|c|c|c|c|c|c|c|c|c|c|c|}
\hline Sociodemographic characteristics & AT & $\mathrm{DE}$ & SE & NL & ES & IT & FR & DK & $\mathrm{CH}$ & $\mathrm{BE}$ & $\mathrm{CZ}$ & ALL \\
\hline Age at interview & 69 & 73 & 70 & 73 & 71 & 72 & 72 & 71 & 70 & 70 & 72 & 69 \\
\hline \multicolumn{13}{|l|}{ Education $(\%)$} \\
\hline No education & 0 & 1 & 0 & 1 & 19 & 5 & 15 & 0 & 0 & 1 & 0 & 8 \\
\hline Primary, lower secondary & 42 & 18 & 42 & 56 & 67 & 73 & 35 & 25 & 39 & 49 & 51 & 49 \\
\hline Upper secondary & 43 & 55 & 31 & 23 & 9 & 19 & 30 & 34 & 54 & 26 & 43 & 28 \\
\hline Tertiary & 15 & 26 & 27 & 20 & 5 & 4 & 21 & 42 & 7 & 23 & 7 & 15 \\
\hline$\%$ Retired & 73 & 67 & 77 & 54 & 31 & 53 & 71 & 65 & 56 & 56 & 86 & 58 \\
\hline \multicolumn{13}{|l|}{ Partnership status (\%) } \\
\hline Single & 8 & 4 & 8 & 5 & 8 & 5 & 8 & 6 & 10 & 4 & 1 & 6 \\
\hline Married or cohabiting & 47 & 63 & 61 & 63 & 66 & 67 & 56 & 57 & 50 & 65 & 56 & 62 \\
\hline Divorced & 10 & 11 & 13 & 10 & 3 & 1 & 13 & 15 & 16 & 8 & 10 & 8 \\
\hline Widow & 35 & 22 & 18 & 22 & 23 & 27 & 24 & 22 & 25 & 23 & 33 & 24 \\
\hline \multicolumn{13}{|l|}{ Number of marriages (\%) } \\
\hline Never & 7 & 4 & 9 & 8 & 8 & 5 & 8 & 6 & 11 & 4 & 1 & 6 \\
\hline 1 Marriage & 85 & 82 & 78 & 84 & 91 & 93 & 84 & 76 & 82 & 87 & 89 & 87 \\
\hline 2+ Marriages & 8 & 14 & 13 & 8 & 1 & 2 & 8 & 17 & 7 & 9 & 10 & 7 \\
\hline$\%$ Ever cohabited & 8 & 9 & 19 & 6 & 2 & 2 & 10 & 20 & 12 & 7 & 5 & 7 \\
\hline$\%$ Ever had a child & 91 & 91 & 91 & 89 & 90 & 91 & 91 & 92 & 84 & 90 & 98 & 91 \\
\hline Number of children & 2 & 2 & 2 & 2 & 3 & 2 & 2 & 2 & 2 & 2 & 2 & 2 \\
\hline Age at first child ${ }^{\mathrm{a}}$ & 24 & 24 & 25 & 26 & 25 & 25 & 25 & 24 & 26 & 25 & 23 & 25 \\
\hline Age at last child ${ }^{\mathrm{a}}$ & 30 & 30 & 30 & 30 & 33 & 31 & 30 & 30 & 30 & 30 & 27 & 31 \\
\hline$\%$ Short birth interval $(<2 \text { years })^{b}$ & 28 & 26 & 15 & 29 & 24 & 18 & 27 & 18 & 31 & 30 & 18 & 24 \\
\hline$\%$ Long birth interval (> 5 years) ${ }^{\mathrm{b}}$ & 33 & 34 & 29 & 18 & 39 & 35 & 32 & 30 & 19 & 22 & 22 & 33 \\
\hline$\%$ Death of a child ${ }^{\mathrm{a}}$ & 12 & 11 & 8 & 7 & 14 & 7 & 9 & 8 & 10 & 12 & 8 & 10 \\
\hline \multicolumn{13}{|l|}{ Early life conditions } \\
\hline$\%$ Parents with high education $^{\mathrm{d}}$ & 52 & 81 & 25 & 20 & 6 & 5 & 25 & 58 & 62 & 23 & 72 & 29 \\
\hline$\%$ Living with both parents ${ }^{\mathrm{c}}$ & 75 & 79 & 84 & 90 & 88 & 91 & 85 & 88 & 91 & 90 & 88 & 86 \\
\hline \# People per bedroom ${ }^{c}$ & 2 & 2 & 2 & 2 & 2 & 3 & 2 & 1 & 1 & 1 & 3 & 2 \\
\hline$\%$ Enough books for a bookshelf ${ }^{c}$ & 27 & 45 & 60 & 45 & 18 & 11 & 34 & 58 & 53 & 34 & 62 & 30 \\
\hline \multicolumn{13}{|l|}{ Housing $^{\mathrm{c}}$} \\
\hline$\%$ Having a fixed bath & 26 & 42 & 50 & 14 & 22 & 20 & 25 & 48 & 51 & 27 & 65 & 28 \\
\hline$\%$ Having cold running water & 56 & 81 & 81 & 89 & 50 & 49 & 73 & 85 & 91 & 63 & 81 & 66 \\
\hline$\%$ Having hot running water & 26 & 29 & 56 & 46 & 16 & 19 & 42 & 49 & 62 & 29 & 17 & 30 \\
\hline$\%$ Having inside toilet & 42 & 54 & 60 & 81 & 40 & 43 & 47 & 66 & 74 & 39 & 69 & 49 \\
\hline$\%$ Having central heating & 6 & 15 & 55 & 6 & 4 & 7 & 22 & 45 & 36 & 13 & 11 & 14 \\
\hline$\%$ Health < "very good" & 35 & 51 & 27 & 49 & 36 & 29 & 40 & 25 & 44 & 31 & 21 & 38 \\
\hline$\%$ Had vaccines in childhood & 95 & 99 & 97 & 86 & 90 & 95 & 96 & 99 & 93 & 95 & 97 & 95 \\
\hline$\%$ With health care source & 91 & 90 & 90 & 97 & 97 & 95 & 93 & 99 & 96 & 97 & 98 & 94 \\
\hline$\%$ Missing school for $1+$ month & 19 & 21 & 12 & 23 & 8 & 7 & 16 & 12 & 16 & 18 & 21 & 14 \\
\hline$\%$ In hospital for $1+$ month & 8 & 11 & 8 & 8 & 2 & 3 & 4 & 7 & 8 & 5 & 8 & 5 \\
\hline \multicolumn{13}{|l|}{ Adult health } \\
\hline$\%$ Long-term illness & 57 & 65 & 58 & 58 & 66 & 50 & 49 & 55 & 35 & 54 & 56 & 56 \\
\hline$\% 1+$ chronic diseases & 81 & 83 & 79 & 77 & 88 & 85 & 83 & 80 & 68 & 83 & 85 & 84 \\
\hline \# Chronic diseases & 2 & 2 & 2 & 2 & 3 & 2 & 2 & 2 & 1 & 2 & 2 & 2 \\
\hline$N$ & 363 & 545 & 716 & 829 & 863 & 991 & 860 & 858 & 519 & 1087 & 658 & 8289 \\
\hline
\end{tabular}

${ }^{\mathrm{a}} \mathrm{Had}$ at least one child

${ }^{\mathrm{b}} \mathrm{Had} 2+$ children

${ }^{\mathrm{c}}$ At age 10

${ }^{\mathrm{d}} \geq$ Upper secondary. Weighted sample 
Table 2 Sociodemographic characteristics and healthdescriptive statistics-men

\begin{tabular}{|c|c|c|c|c|c|c|c|c|c|c|c|c|}
\hline Sociodemographic characteristics & AT & $\mathrm{DE}$ & $\mathrm{SE}$ & NL & ES & IT & FR & DK & $\mathrm{CH}$ & $\mathrm{BE}$ & $\mathrm{CZ}$ & ALL \\
\hline Age at interview & 71 & 70 & 71 & 69 & 71 & 71 & 70 & 69 & 69 & 70 & 69 & 70 \\
\hline \multicolumn{13}{|l|}{ Education (\%) } \\
\hline No education & 0 & 0 & 0 & 0 & 16 & 1 & 9 & 0 & 0 & 1 & 0 & 5 \\
\hline Primary, lower secondary & 17 & 6 & 45 & 38 & 66 & 70 & 25 & 14 & 22 & 41 & 48 & 41 \\
\hline Upper secondary & 53 & 57 & 30 & 30 & 8 & 22 & 39 & 47 & 64 & 28 & 34 & 32 \\
\hline Tertiary & 29 & 37 & 25 & 31 & 10 & 7 & 27 & 39 & 14 & 30 & 18 & 21 \\
\hline$\%$ Retired & 90 & 75 & 69 & 68 & 74 & 83 & 78 & 59 & 56 & 81 & 78 & 77 \\
\hline \multicolumn{13}{|l|}{ Partnership status (\%) } \\
\hline Single & 7 & 9 & 8 & 7 & 12 & 7 & 7 & 10 & 6 & 5 & 3 & 8 \\
\hline Married or cohabiting & 79 & 76 & 75 & 80 & 79 & 83 & 77 & 70 & 77 & 82 & 85 & 79 \\
\hline Divorce & 6 & 6 & 10 & 7 & 4 & 3 & 8 & 12 & 11 & 5 & 5 & 6 \\
\hline Widov & 7 & 8 & 7 & 6 & 5 & 6 & 8 & 8 & 6 & 8 & 8 & 7 \\
\hline \multicolumn{13}{|l|}{ Number of marriages (\%) } \\
\hline Never & 7 & 9 & 12 & 11 & 13 & 8 & 7 & 9 & 8 & 5 & 2 & 9 \\
\hline 1 Marriage & 83 & 78 & 73 & 80 & 84 & 88 & 80 & 75 & 78 & 87 & 85 & 83 \\
\hline 2+ Marriages & 11 & 12 & 16 & 9 & 3 & 4 & 13 & 16 & 14 & 8 & 13 & 9 \\
\hline$\%$ Ever cohabited & 8 & 9 & 24 & 7 & 3 & 5 & 12 & 22 & 17 & 8 & 3 & 8 \\
\hline$\%$ Ever had a child & 87 & 84 & 88 & 84 & 84 & 88 & 90 & 86 & 84 & 89 & 96 & 87 \\
\hline Number of children & 2 & 2 & 2 & 2 & 2 & 2 & 2 & 2 & 2 & 2 & 2 & 2 \\
\hline Age at first child ${ }^{\mathrm{a}}$ & 27 & 28 & 28 & 29 & 28 & 29 & 27 & 27 & 29 & 27 & 26 & 28 \\
\hline Age at last child ${ }^{\mathrm{a}}$ & 33 & 32 & 33 & 33 & 35 & 35 & 33 & 32 & 34 & 32 & 30 & 34 \\
\hline$\%$ Short birth interval $(<2 \text { years })^{\mathrm{b}}$ & 28 & 21 & 15 & 28 & 25 & 16 & 22 & 15 & 26 & 28 & 15 & 21 \\
\hline$\%$ Long birth interval ( $>5$ years $)^{b}$ & 37 & 31 & 30 & 15 & 40 & 37 & 32 & 29 & 20 & 19 & 22 & 32 \\
\hline$\%$ Death of a child ${ }^{a}$ & 6 & 5 & 6 & 7 & 11 & 7 & 6 & 5 & 6 & 9 & 4 & 7 \\
\hline \multicolumn{13}{|l|}{ Early life conditions } \\
\hline$\%$ Parents with high education ${ }^{\mathrm{d}}$ & 62 & 85 & 24 & 21 & 4 & 6 & 26 & 60 & 64 & 21 & 73 & 30 \\
\hline$\%$ Living with both parents ${ }^{\mathrm{c}}$ & 82 & 75 & 83 & 89 & 89 & 91 & 86 & 89 & 88 & 90 & 91 & 86 \\
\hline \# People per bedroom ${ }^{\mathrm{c}}$ & 2 & 2 & 2 & 2 & 2 & 3 & 2 & 1 & 1 & 1 & 2 & 2 \\
\hline$\%$ Enough books for a bookshelf ${ }^{c}$ & 29 & 46 & 61 & 45 & 18 & 10 & 35 & 58 & 50 & 30 & 58 & 30 \\
\hline \multicolumn{13}{|l|}{ Housing $^{\mathrm{c}}$} \\
\hline$\%$ Having & 27 & 36 & 62 & 14 & 21 & 19 & 29 & 53 & 57 & 22 & 68 & 28 \\
\hline$\%$ Having c & 58 & 84 & 86 & 92 & 52 & 48 & 76 & 87 & 92 & 68 & 80 & 68 \\
\hline$\%$ Having & 23 & 26 & 66 & 50 & 19 & 17 & 45 & 55 & 65 & 27 & 21 & 31 \\
\hline$\%$ Having inside toilet & 40 & 54 & 68 & 82 & 40 & 40 & 50 & 70 & 75 & 41 & 71 & 50 \\
\hline$\%$ Having central heating & 7 & 15 & 63 & 8 & 4 & 5 & 23 & 49 & 44 & 11 & 14 & 15 \\
\hline$\%$ Health < "very good" & 32 & 50 & 23 & 45 & 36 & 24 & 38 & 20 & 32 & 28 & 21 & 35 \\
\hline$\%$ Had vaccines in childhood & 97 & 96 & 97 & 90 & 84 & 95 & 98 & 99 & 94 & 97 & 97 & 94 \\
\hline$\%$ With health care source & 91 & 86 & 90 & 98 & 95 & 94 & 92 & 100 & 96 & 98 & 99 & 93 \\
\hline$\%$ Missing school for $1+$ month & 18 & 20 & 12 & 17 & 9 & 7 & 16 & 12 & 17 & 16 & 20 & 13 \\
\hline$\%$ In hospital for $1+$ month & 11 & 10 & 8 & 9 & 2 & 3 & 6 & 10 & 7 & 4 & 7 & 6 \\
\hline \multicolumn{13}{|l|}{ Adult health } \\
\hline$\%$ Long-term illness & 53 & 67 & 48 & 48 & 58 & 43 & 49 & 50 & 33 & 47 & 54 & 52 \\
\hline$\% 1+$ chronic diseases & 79 & 85 & 73 & 70 & 85 & 79 & 81 & 74 & 65 & 76 & 87 & 80 \\
\hline \# Chronic diseases & 2 & 2 & 1 & 1 & 2 & 2 & 2 & 2 & 1 & 2 & 2 & 2 \\
\hline$N$ & 238 & 482 & 575 & 632 & 693 & 803 & 633 & 700 & 386 & 852 & 426 & 6420 \\
\hline
\end{tabular}

${ }^{\mathrm{a}} \mathrm{Had}$ at least one child

${ }^{\mathrm{b}} \mathrm{Had} 2+$ children

${ }^{c}$ At age 10

${ }^{\mathrm{d}} \geq$ Upper secondary. Weighted sample 
Fig. 1 Logistic regressionlong-term illness

\section{Long-Term Illness 2013, Odds Ratio}

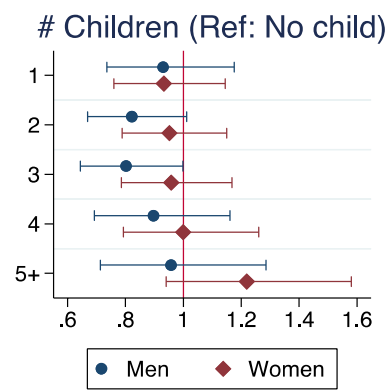

Short Birth Interval (Ref: No)

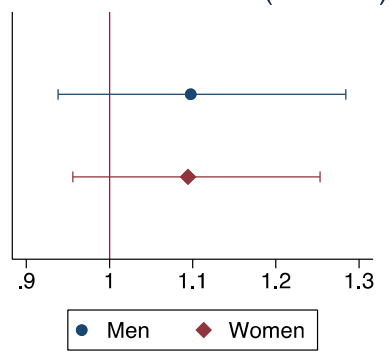

Long Birth Interval (Ref: No)
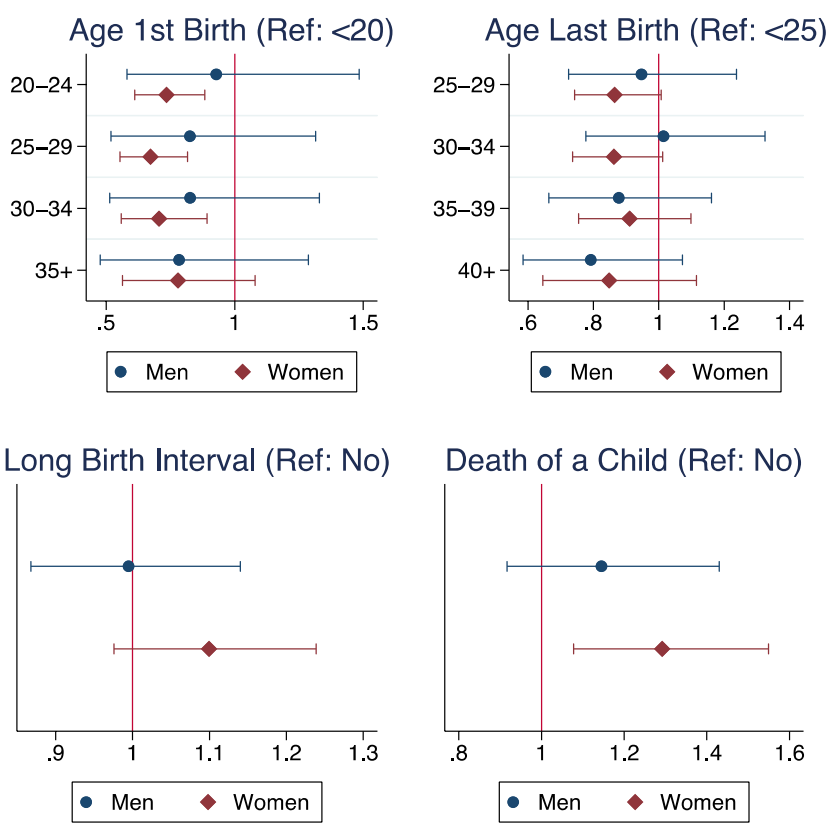

Switzerland (35.2\% for women; $33.1 \%$ for men) and Italy (48.6\% for women; $42.5 \%$ for men) and highest in Germany (64.8\% for women; $66.9 \%$ for men) and Spain (66.2\% for women; $58 \%$ for men). This heterogeneity was reflected also when looking at diagnosed chronic diseases. In Switzerland, there was the lowest prevalence of chronic diseases for both men and women (e.g. $67.5 \%$ and 1.2 conditions on average among women). The highest prevalence and number of chronic diseases were observed in Spain and Czech Republic for women and in Germany and Czech Republic for men.

More than $82 \%$ of the sample had been married at least once, and more than $87 \%$ had at least one child. Women had on average 2.4 children, while men had 2.2 children. The level of childlessness was highest in Switzerland and the Netherlands and lowest in Czech Republic among women, while it was more homogeneous among men. The mean age at first birth ranged between 23.2 (Czech Republic) and 25.9 years (Switzerland) for women, and between 25.8 (Belgium) and 29.3 years (Switzerland) among men. The highest age at last birth was reported in Spain (32.6 and 35.1 years for women and men, respectively), while the lowest in Czech Republic (27.4 and 30.0 years for women and men, respectively). Just below one-fourth (23.7\%) of women and $21 \%$ of men experienced short birth intervals, $32.5 \%$ of women and $32 \%$ of men experienced long birth intervals, and $9.7 \%$ of women and $7.1 \%$ of men experienced the death of a child.

Tables 1 and 2 show a great level of heterogeneity in early life conditions and childhood health. For example, 5\% of the respondents in Italy and Spain had parents with a high level of education, compared to $80 \%$ of the respondents in Germany. The proportion of those who missed school or that were hospitalized for more than a month when 10 years old was lowest in Italy and Spain and highest in Germany, the Netherlands, and Czech Republic.

\section{Multivariate results (pooled sample)}

The results for the multivariate regressions on self-reported long-term illness are reported in Fig. 1. The number of children was not relevant for the presence of long-term illnesses among women, and among men, a J-shaped relationship was observed, but the odds ratios were not significantly different from zero. Age at first birth was important among women, since those who had their first child after age 20 and before age 35 had a lower probability of reporting long-term illnesses. Age at last birth and short and long birth intervals did not have any significant association with the probability of having a long-term illness. Experiencing the death of a child was associated with a higher risk of long-term chronic conditions only among women.

When looking at the prevalence of diagnosed chronic diseases (Fig. 2), the results were very similar to those found on self-reported illness, except for one notable difference. The number of children was significant for men-i.e. childless men had a higher probability of reporting chronic diseases than men with children, and the odds ratios for those with one, two, three, or four children were very similar to each other, even though only the odds ratios for men with two and three children were statistically significant.

The only significant result for the model studying number of chronic diseases (Fig. 3) was that the prevalence rate for women who had their first child after age 20 was lower than 
Fig. 2 Logistic regressionchronic disease
1+ Chronic Diseases 2013, Odds Ratio

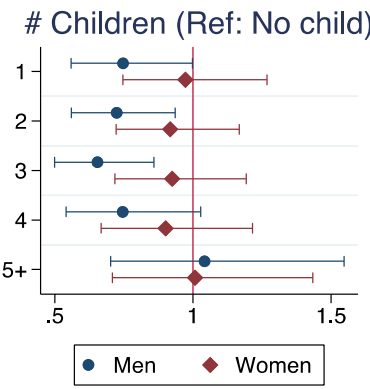

Short Birth Interval (Ref: No)

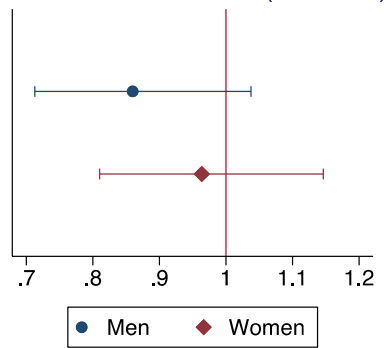

Long Birth Interval (Ref: No)

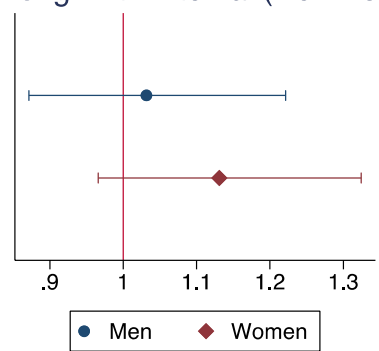

Fig. 3 Negative binomial regression-number of chronic diseases

\section{Number of Chronic Diseases 2013, IRRs}

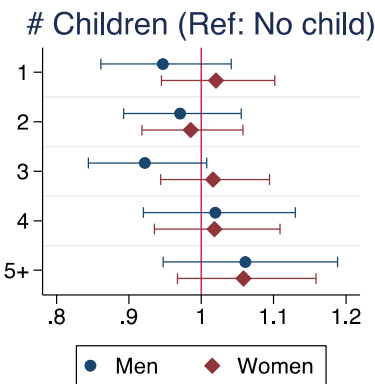

Short Birth Interval (Ref: No)

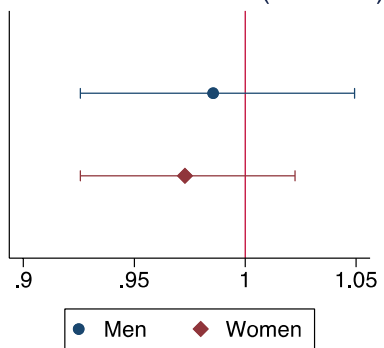

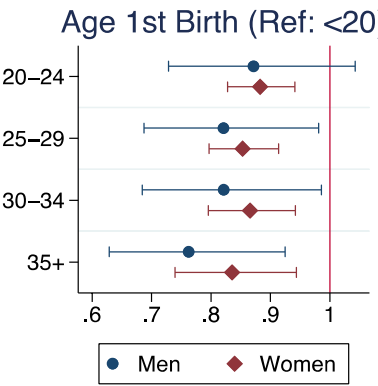

Long Birth Interval (Ref: No)

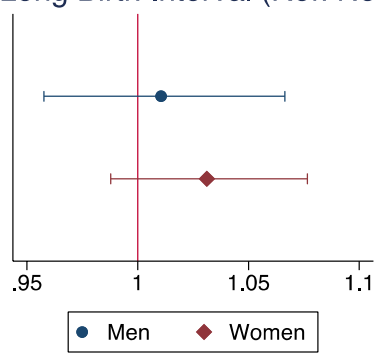

Death of a Child (Ref: No)
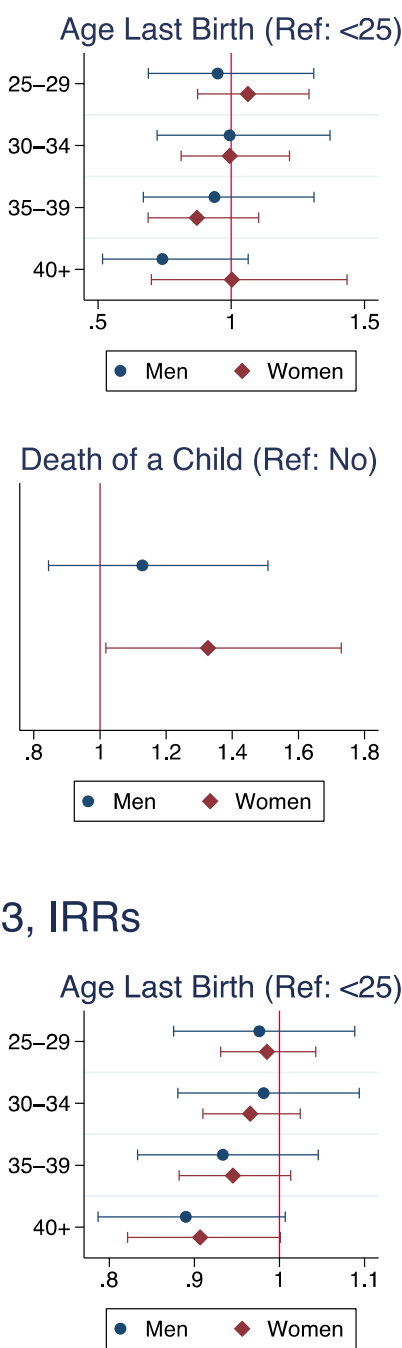

Death of a Child (Ref: No)

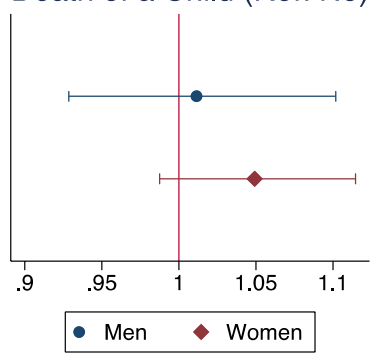

for those who experienced a teenage pregnancy. The same was true for men who had their first child after age 25 .

\section{Multivariate results (by country)}

Tables 3 and 4 report the results by country for models studying self-reported long-term illnesses, for women and men, respectively, while Tables 5 and 6 report the results for diagnosed chronic diseases. There was a higher probability of having a long-term illness among women who had 5 or more children in Austria and France (OR 5.59 and OR 2.73, $p$ value $<0.05$, respectively), while the results were not significant for men. These associations were not significant in Southern and Eastern European countries. The results for age at first birth showed a U-shaped relationship between age at first birth and the risk of reporting a long-term illness among women in Sweden (OR, age 20-24=0.52, OR, age $25-29=0.467, \mathrm{OR}$, age $30-34=0.455, p$ value $<0.05)$ 
Table 3 Long-term illness multivariate regressions-women

\begin{tabular}{|c|c|c|c|c|c|c|c|c|c|c|c|}
\hline $\begin{array}{l}\text { Long-term ill- } \\
\text { ness (yes vs. no) }\end{array}$ & AT & $\mathrm{DE}$ & SE & NL & ES & IT & FR & DK & $\mathrm{CH}$ & $\mathrm{BE}$ & $\mathrm{CZ}$ \\
\hline \multicolumn{12}{|c|}{$\#$ of Children (ref. $=0$ ) } \\
\hline 1 Child & 1.31 & 1.545 & 0.877 & 0.638 & 0.613 & 0.873 & 1.046 & 1.174 & 1.725 & 1.081 & 0.677 \\
\hline 2 Children & 1.482 & 1.393 & 0.912 & 0.618 & 0.759 & 0.821 & 1.246 & 0.968 & 1.353 & 1.023 & 0.986 \\
\hline 3 Children & 1.327 & 0.832 & 1.137 & 0.617 & 0.664 & 1.118 & 1.263 & 1.071 & 1.459 & 0.993 & 0.651 \\
\hline 4 Children & 1.787 & 1.462 & 1.42 & 0.565 & 0.608 & 1.197 & 1.306 & 0.763 & 1.185 & 1.084 & 1.133 \\
\hline 5+ Children & $5.592 * *$ & 1.845 & 0.833 & $0.468^{*}$ & 1.032 & 0.949 & $2.733 * *$ & 1.531 & 1.153 & 1.201 & 1.159 \\
\hline$N$ & 363 & 545 & 716 & 829 & 863 & 991 & 860 & 858 & 519 & 1087 & 658 \\
\hline \multicolumn{12}{|c|}{ Age at 1 st birth $($ ref. $<20)$} \\
\hline $20-24$ & 0.88 & 0.742 & $0.520 * *$ & 0.581 & 0.496 & 0.799 & 0.627 & $0.600 *$ & 1.142 & 0.916 & 0.965 \\
\hline $25-29$ & 0.913 & 0.807 & $0.467 * *$ & $0.508^{*}$ & $0.465^{*}$ & 0.642 & 0.7 & $0.474 * *$ & 1.024 & 0.88 & 0.645 \\
\hline $30-34$ & 1.244 & 0.603 & $\mathrm{0.455}^{* *}$ & $0.471 *$ & 0.461 & 1.084 & 0.935 & 0.736 & 0.411 & 0.794 & 0.598 \\
\hline $35+$ & $7.049 *$ & 3.701 & 0.822 & $0.313 * *$ & 0.526 & 1.086 & $0.297 * *$ & 0.72 & 1.872 & 0.504 & 0.654 \\
\hline \multicolumn{12}{|c|}{ Age at last birth (ref. $<25)$} \\
\hline $25-29$ & 1.762 & 1.285 & 0.732 & 0.789 & 0.946 & 0.794 & 0.676 & 0.968 & 0.605 & $0.610 * *$ & 0.949 \\
\hline $30-34$ & $2.646 * *$ & 1.294 & 0.648 & 0.643 & 0.61 & 1.15 & 0.707 & 0.957 & $0.513 *$ & 0.699 & 0.784 \\
\hline $35-39$ & 1.583 & 1.801 & 0.749 & 0.932 & 0.564 & 0.814 & 0.751 & 1.235 & $0.439 *$ & 0.695 & 1.638 \\
\hline $40+$ & 2.492 & 1.2 & 0.581 & 0.824 & $0.405^{* *}$ & 1.071 & 0.677 & 1.415 & 0.8 & 0.537 & 1.725 \\
\hline$N$ & 332 & 497 & 663 & 744 & 787 & 908 & 781 & 792 & 438 & 973 & 637 \\
\hline \multicolumn{12}{|c|}{ Short birth interval (ref.: no) } \\
\hline Yes & 1.3 & 1.632 & 1.31 & $1.451^{*}$ & 1.255 & 0.923 & 0.881 & 1.102 & 0.755 & 1.095 & 0.84 \\
\hline \multicolumn{12}{|c|}{ Long birth interval (ref.: no) } \\
\hline Yes & 1.266 & 1.056 & 1.146 & 1.302 & 1.054 & 1.024 & 0.992 & 0.97 & 0.942 & 1 & $1.799 * *$ \\
\hline$N$ & 263 & 397 & 572 & 667 & 715 & 738 & 623 & 686 & 375 & 782 & 532 \\
\hline \multicolumn{12}{|c|}{ Death of a child (ref.: no) } \\
\hline Yes & 0.824 & $2.454 * *$ & 1.657 & 1.196 & 1.51 & 1.128 & 0.901 & 1.641 & $2.070 *$ & 1.114 & 0.769 \\
\hline$N$ & 332 & 497 & 663 & 744 & 787 & 908 & 781 & 792 & 438 & 973 & 637 \\
\hline
\end{tabular}

Bold values reflect odd ratios that are significant at least at 5\% level, i.e. $p<0.05$

Odds ratios reported in the table; ${ }^{*} p<0.10,{ }^{* *} p<0.05,{ }^{* * *} p<0.01$

and Denmark (OR, age 25-29 $=0.474, p$ value $<0.05$ ), and a negative association (higher age at first birth, lower risk of long-term illness) among women in the Netherlands $(\mathrm{OR}$, age $35+=0.313, p$ value $<0.05)$ and France (OR, age $35+=0.297, p$ value $<0.05)$. Among men, a $U$-shaped relationship was found in Switzerland (OR, age 20-24 $=0.067$, $p$ value $<0.05$ ), while an inverted $\mathrm{U}$-shaped relationship was found in Spain (OR, age 20-24=9.222 $p$ value $<0.05)$. Age at last birth had a negative association with chronic conditions in Spain (OR, age 40+ $=0.405, p$ value $<0.05$ ), a U-shaped association in Belgium (OR, age 25-29 $=0.61$, $p$ value $<0.05$ ), and an inverted $\mathrm{U}$-shaped association in Austria (OR, age $30-34=2.646, p$ value $<0.05)$ among women, while there was no significant relationship among men. Short birth intervals were associated with an increased risk of long-term illness among men in the Netherlands (OR $1.838, p$ value $<0.05$ ). Long birth intervals were associated with a higher risk of long-term illness among women in Czech Republic (OR 1.799, $p$ value $<0.05$ ) and a lower risk among men in Belgium (OR 0.609, $p$ value $<0.05$ ). Experiencing the death of a child increased the risk of long-term illness among women in Germany and among men in the Netherlands.

Moving to Tables 5 and 6, the results for number of children and for age at last birth did not show any significant association with the risk of having a chronic disease, neither for women nor for men. There was a U-shaped association between age at first birth and the risk of being diagnosed with a chronic disease among Swedish (OR, age 20-24 $=0.357$, $p$ value $<0.05$, OR, age $25-29=0.291, p$ value $<0.01$ ) and French (OR, age 20-24 $=0.357, p$ value $<0.05)$ women, a negative association among Czech women (OR, age $35+=0.127, p$ value $<0.05$ ), and an inverted $\mathrm{U}$-shaped association among Danish men (OR, age 20-24 $=6.573$, OR, age $25-29=8.363$, OR, age 30-34 $=5.650, p$ value $<0.05$ ). Also, there was no association between short birth intervals and chronic diseases for women, while short birth intervals decreased the risk of chronic diseases for men in Belgium 
Table 4 Long-term illness multivariate regressions-men

\begin{tabular}{|c|c|c|c|c|c|c|c|c|c|c|c|}
\hline $\begin{array}{l}\text { Long-term illness } \\
\text { (yes vs. no) }\end{array}$ & AT & DE & SE & NL & ES & IT & FR & DK & $\mathrm{CH}$ & $\mathrm{BE}$ & $\mathrm{CZ}$ \\
\hline \multicolumn{12}{|c|}{$\#$ of Children (ref. $=0$ ) } \\
\hline 1 Child & 0.406 & 0.611 & 1.239 & 1.046 & 0.529 & 0.695 & 1.143 & 0.796 & 1.001 & 1.62 & 1.187 \\
\hline 2 Children & 0.31 & 0.978 & 1.184 & 0.905 & 0.559 & 0.697 & 0.733 & 0.774 & 0.633 & 1.234 & 0.848 \\
\hline 3 Children & 0.257 & 0.842 & 0.724 & 0.698 & $0.436 *$ & 0.699 & 0.91 & 0.986 & 0.783 & 1.314 & 0.867 \\
\hline 4 Children & $0.201 *$ & 0.994 & 1.669 & 0.65 & 0.578 & 0.578 & 0.998 & 0.584 & 1.955 & 1.488 & 1.073 \\
\hline 5+ Children & 0.313 & 0.431 & 1.166 & 1.379 & 0.641 & 0.722 & 1.397 & 1.345 & $0.112 *$ & 1.228 & 2.904 \\
\hline$N$ & 238 & 482 & 575 & 632 & 693 & 803 & 633 & 700 & 386 & 852 & 426 \\
\hline \multicolumn{12}{|c|}{ Age at 1 st birth $($ ref. $<20)$} \\
\hline $20-24$ & 0.31 & 0.759 & 0.545 & 0.862 & $9.222 * *$ & 0.266 & 0.941 & 3.648 & $0.067 * *$ & 0.979 & 1.657 \\
\hline $25-29$ & 0.466 & 0.601 & 0.466 & 0.45 & $4.601^{*}$ & 0.261 & 0.922 & 3.368 & $0.080^{*}$ & 0.999 & 1.501 \\
\hline $30-34$ & 0.349 & 0.552 & 0.496 & 0.551 & 3.652 & 0.238 & 1.134 & 3.343 & 0.188 & 0.859 & 1.118 \\
\hline $35+$ & 0.249 & 0.34 & 0.407 & 0.773 & 4.188 & 0.313 & 0.873 & 1.852 & $0.082^{*}$ & 1.201 & 0.558 \\
\hline \multicolumn{12}{|c|}{ Age at last birth $($ ref. $<25)$} \\
\hline $25-29$ & 0.991 & 1.161 & 0.865 & 1.112 & 0.923 & 2.423 & 1.981 & 1.466 & 0.376 & 0.811 & 0.636 \\
\hline $30-34$ & 1.466 & 0.942 & 0.864 & 0.639 & 0.677 & 2.704 & $2.412 *$ & 1.744 & 0.557 & 0.887 & 1.267 \\
\hline $35-39$ & 0.941 & 0.566 & 0.688 & 1.265 & 0.585 & 2.591 & 1.844 & 1.511 & 0.582 & 0.736 & 0.47 \\
\hline $40+$ & 0.576 & 0.588 & 0.522 & 0.838 & 0.609 & 2.1 & 2.336 & 0.844 & 0.403 & 0.693 & 0.32 \\
\hline$N$ & 208 & 418 & 516 & 548 & 603 & 727 & 567 & 615 & 329 & 757 & 407 \\
\hline \multicolumn{12}{|c|}{ Short birth interval (ref.: no) } \\
\hline Yes & 1.332 & 1.139 & 1.202 & $1.838 * *$ & 1.151 & 1.265 & 0.856 & 0.958 & 0.989 & 0.863 & 1.124 \\
\hline \multicolumn{12}{|c|}{ Long birth interval (ref.: no) } \\
\hline Yes & 0.935 & 1.047 & 0.834 & 1.337 & 0.973 & 0.908 & 1.277 & $1.460^{*}$ & 0.946 & $0.609 * *$ & 1.156 \\
\hline$N$ & 166 & 324 & 458 & 490 & 545 & 589 & 483 & 544 & 291 & 615 & 344 \\
\hline \multicolumn{12}{|c|}{ Death of a child (ref.: no) } \\
\hline Yes & 1.241 & 2.17 & 0.847 & $3.635 * * *$ & 1.553 & 0.988 & 0.62 & 0.737 & 0.5 & 1.413 & 1.028 \\
\hline$N$ & 208 & 418 & 516 & 548 & 603 & 727 & 567 & 615 & 329 & 757 & 407 \\
\hline
\end{tabular}

Bold values reflect odd ratios that are significant at least at 5\% level, i.e. $p<0.05$

Odds ratios reported in the table; $* p<0.10$, $* * p<0.05$, *** $p<0.01$

(OR $0.569, p$ value $<0.05$ ). Long birth intervals increased the risk of chronic diseases in the Netherlands for women and in Austria for men, while experiencing the death of a child was associated with a higher risk of chronic conditions among women in Switzerland and a lower risk among men in Czech Republic.

\section{Discussion}

Analysing the relationship between fertility histories and chronic conditions later in life is necessary to understand the biosocial determinants of health and shed light on critical elements of the ageing process. This study extends the current body of literature by demonstrating the value of investigating cross-national differences in the association between fertility histories and the prevalence of chronic conditions, and to look at different measures of such chronic conditions. The results indicate that in European countries, age at first birth is more relevant to predict health outcomes than number of children, which has been more frequently used in the literature (see e.g. Dior et al. 2013; Engelman et al. 2010; Hardy et al. 2007). In most countries, women who experienced teenage pregnancy show a higher risk of developing chronic conditions later in life. This is likely due to the fact that young parents have fewer resources and social support to deal with the stress of parenthood and to cope with the economic strain of the situation (Falci et al. 2010). The negative consequences of teenage pregnancy can cumulate over the life course and result in worse health outcomes later in life, as hypothesized by the aforementioned life course models. The weaker association between parity and chronic conditions in older ages can also be explained by the fact that in European countries, the low variation in fertility rates might not be sufficient to detect effects that could be observed in populations with higher levels of fertility.

However, there are important gender differences, as results show that the number of children is more important 
Table 5 Chronic diseases multivariate regressions-women

\begin{tabular}{|c|c|c|c|c|c|c|c|c|c|c|c|}
\hline $\begin{array}{l}\text { Chronic disease } \\
\text { (yes vs. no) }\end{array}$ & AT & $\mathrm{DE}$ & SE & NL & ES & IT & FR & DK & $\mathrm{CH}$ & $\mathrm{BE}$ & $\mathrm{CZ}$ \\
\hline \multicolumn{12}{|c|}{$\#$ of Children (ref. $=0$ ) } \\
\hline 1 Child & 1.29 & 1.507 & 0.863 & $0.479^{*}$ & 0.84 & 0.641 & 1.241 & 1.331 & 1.75 & 1.376 & 0.703 \\
\hline 2 Children & 1.388 & 1.038 & 1.149 & 0.583 & 0.493 & 0.735 & 1.504 & 1.141 & 0.67 & 1.088 & 0.996 \\
\hline 3 Children & 0.696 & 0.612 & 1.238 & 0.796 & 0.371 & 0.743 & 1.744 & 0.921 & 1.249 & 1.042 & 0.828 \\
\hline 4 Children & 1.453 & 1.031 & 1.359 & $0.476^{*}$ & 0.604 & 0.792 & 1.226 & 1.099 & 0.767 & 0.844 & 1.232 \\
\hline 5+ Children & 1.3 & 0.856 & 1.408 & 0.637 & 0.363 & 1.434 & $2.639^{*}$ & 2.147 & 1.791 & 0.6 & 0.858 \\
\hline$N$ & 363 & 545 & 716 & 829 & 863 & 991 & 860 & 858 & 519 & 1087 & 658 \\
\hline \multicolumn{12}{|c|}{ Age at 1st birth $($ ref. $<20)$} \\
\hline $20-24$ & $0.433^{*}$ & 0.814 & $0.357 * *$ & 0.596 & 0.629 & 1.102 & $0.357 * *$ & 0.934 & 0.677 & 1.19 & 0.68 \\
\hline $25-29$ & $0.332 *$ & 0.85 & $0.291 * * *$ & 0.608 & 0.408 & 1.095 & $0.412 *$ & 0.709 & 0.773 & 1.256 & 0.464 \\
\hline $30-34$ & 1.241 & 0.635 & $0.408 *$ & 0.449 & 0.391 & 1.064 & 0.669 & 0.908 & 0.503 & 2.291 & 0.555 \\
\hline $35+$ & 0.638 & 1 & 0.59 & $0.330^{*}$ & 1 & 0.922 & 0.466 & 0.684 & 1.011 & 2.091 & $0.127 * *$ \\
\hline \multicolumn{12}{|c|}{ Age at last birth (ref. $<25)$} \\
\hline $25-29$ & 1.207 & 1.575 & 0.865 & 1.338 & 1.428 & 0.972 & 1.029 & 1.293 & 0.628 & 1.181 & 0.896 \\
\hline $30-34$ & 1.204 & 1.045 & 0.669 & 1.477 & 1.012 & 1.134 & 0.934 & 0.955 & 0.58 & 1.612 & 0.654 \\
\hline $35-39$ & 0.903 & 1.153 & 0.632 & 1.248 & 1.334 & 0.782 & 0.947 & 0.897 & $0.407 *$ & 1.27 & 0.597 \\
\hline $40+$ & 1 & 0.513 & 0.537 & 1.59 & 1.333 & 0.631 & 1.886 & 0.99 & 0.388 & 1.514 & 1.152 \\
\hline$N$ & 332 & 497 & 663 & 744 & 787 & 908 & 781 & 792 & 438 & 973 & 637 \\
\hline \multicolumn{12}{|c|}{ Short birth interval (ref.: no) } \\
\hline Yes & $2.650^{*}$ & 1.34 & 0.948 & 0.899 & 1.164 & 0.845 & 0.895 & 1.173 & 0.942 & 1.165 & 0.567 \\
\hline \multicolumn{12}{|c|}{ Long birth interval (ref.: no) } \\
\hline Yes & 1.451 & 0.758 & 1.568 & $2.338 * *$ & 1.464 & 1.162 & 1.032 & 1.147 & 0.829 & $0.646^{*}$ & 0.932 \\
\hline$N$ & 263 & 397 & 572 & 667 & 715 & 738 & 623 & 686 & 375 & 782 & 532 \\
\hline \multicolumn{12}{|c|}{ Death of a child (ref.: no) } \\
\hline Yes & 0.578 & 2.208 & 1.93 & 1.137 & 1.083 & 1.298 & 0.668 & 1.942 & $2.980 * *$ & 1.216 & 1 \\
\hline$N$ & 332 & 497 & 663 & 744 & 787 & 908 & 781 & 792 & 438 & 973 & 637 \\
\hline
\end{tabular}

Bold values reflect odd ratios that are significant at least at 5\% level, i.e. $p<0.05$

Odds ratios reported in the table; ${ }^{*} p<0.10,{ }^{* *} p<0.05,{ }^{* * *} p<0.01$

for men and the death of a child is more important for women. Differences can also be observed across measures of health; for men, the number of children is significant only when looking at the prevalence of diagnosed chronic diseases, and age at first birth is significant only when looking at the number of chronic diseases. In addition, the association with chronic conditions exists only for some fertility characteristics, like parity and age at first birth, but for other variables-like length of birth intervals and age at last birth - the results are mixed and less clear.

Overall, the findings confirm the hypotheses introduced by several life course theories and by the health development model (Halfon and Hochstein 2002; Kuh and Shlomo 2004; Kuh et al. 2013). It is necessary to consider life course trajectories and their cumulative effects to understand health later in life and the ageing process. Moreover, findings show cross-country heterogeneity. In socio-democratic and continental countries, the association between fertility and chronic conditions - in particular between age at first birth and long-term illnesses-is statistically significant among women but not among men (except for Denmark), suggesting a stronger physiological link between fertility and health later in life. The fact that the association is significant only among women in these countries suggests an attenuation of negative social mechanisms related to parenthood (e.g. economic strain, stress), possibly through a more generous welfare system and more egalitarian gender norms. Given the less generous welfare regimes and lower gender equality in Southern and Eastern Europe, larger associations were expected in these countries; however, it was not the case. According to Esping-Andersen's welfare regime theory (2013), welfare states have the power to influence individual behaviour and can be associated with different life course trajectories. In Scandinavian countries, where social benefits are large, life course trajectories tend to be more heterogeneous, fertility rates higher, gender equality fostered by social and childcare policies, and the national health care system can reduce health inequality at older ages. 
Table 6 Chronic diseases multivariate regressions-men

\begin{tabular}{|c|c|c|c|c|c|c|c|c|c|c|c|}
\hline $\begin{array}{l}\text { Chronic disease } \\
\text { (yes vs. no) }\end{array}$ & AT & $\mathrm{DE}$ & SE & NL & ES & IT & FR & DK & $\mathrm{CH}$ & $\mathrm{BE}$ & $\mathrm{CZ}$ \\
\hline \multicolumn{12}{|c|}{$\#$ of Children (ref. $=0$ ) } \\
\hline 1 Child & 0.315 & 0.59 & 2.014 & 0.686 & 1.184 & 0.968 & 1.107 & 0.98 & 0.682 & 0.895 & 0.319 \\
\hline 2 Children & 0.398 & 1.56 & 1.226 & $0.517 *$ & 1.225 & 1.299 & 0.67 & 0.781 & $0.410^{*}$ & 0.745 & 0.35 \\
\hline 3 Children & 0.319 & 0.915 & 0.706 & $0.503 *$ & 0.725 & 0.781 & 1.138 & 1.049 & 0.489 & 0.679 & 0.266 \\
\hline 4 Children & 0.249 & 0.607 & 1.032 & 0.468 & 1.58 & 0.997 & 0.831 & 0.977 & 0.91 & 0.913 & 1 \\
\hline 5+ Children & 0.454 & 0.425 & $4.227 *$ & 0.557 & 1.635 & 2.728 & 0.94 & 1.229 & 0.558 & 1.608 & 0.068 \\
\hline$N$ & 238 & 482 & 575 & 632 & 693 & 803 & 633 & 700 & 386 & 852 & 426 \\
\hline \multicolumn{12}{|c|}{ Age at 1 st birth $($ ref. $<20)$} \\
\hline $20-24$ & 0.295 & 1.225 & 0.409 & 1.616 & 3.102 & 2.754 & 0.247 & $6.573 * *$ & 1.529 & $8.336^{*}$ & 0.533 \\
\hline $25-29$ & 0.272 & 1.568 & 0.378 & 1.495 & 0.927 & 2.078 & 0.322 & $8.363 * *$ & $1.979 *$ & $7.830^{*}$ & 0.518 \\
\hline $30-34$ & 0.377 & 1.227 & 0.459 & 1.359 & 0.891 & 2.218 & 0.321 & $5.650 * *$ & 1.608 & $7.651^{*}$ & 0.695 \\
\hline $35+$ & 1 & 1 & 0.259 & 2.597 & 0.543 & 2.948 & 0.205 & $4.794 *$ & 1 & $7.309^{*}$ & 0.691 \\
\hline \multicolumn{12}{|c|}{ Age at last birth (ref. $<25)$} \\
\hline $25-29$ & 0.672 & 2.416 & 0.673 & 1.236 & 0.668 & 0.469 & 1.402 & 1.696 & 0.761 & 1.555 & 0.428 \\
\hline $30-34$ & 1.486 & 1.638 & 0.521 & 0.906 & 0.558 & 0.669 & 1.646 & 1.765 & 0.915 & 1.599 & 0.582 \\
\hline $35-39$ & 3.142 & 1.754 & 0.389 & 1.477 & 0.443 & 0.643 & 0.867 & 1.476 & 0.541 & 1.223 & 1.056 \\
\hline $40+$ & 0.931 & 1.145 & $0.319^{*}$ & 1.291 & 0.302 & 0.705 & 0.858 & 1.105 & 0.255 & 1.676 & 0.211 \\
\hline$N$ & 208 & 418 & 516 & 548 & 603 & 727 & 567 & 615 & 329 & 757 & 407 \\
\hline \multicolumn{12}{|c|}{ Short birth interval (ref.: no) } \\
\hline Yes & 0.653 & 1.013 & 0.787 & 1.277 & 1.608 & $0.585^{*}$ & 1.821 & 1.218 & $0.559 *$ & $0.569 * *$ & 0.946 \\
\hline \multicolumn{12}{|c|}{ Long birth interval (ref.: no) } \\
\hline Yes & $4.095 * *$ & 0.912 & 0.766 & 1.648 & 0.82 & 1.315 & 0.997 & 1.104 & 0.6 & 0.961 & 1.344 \\
\hline$N$ & 166 & 324 & 458 & 490 & 545 & 589 & 483 & 544 & 291 & 615 & 344 \\
\hline \multicolumn{12}{|c|}{ Death of a child (ref.: no) } \\
\hline Yes & 0.7 & 1.358 & 1.057 & 1.298 & 1.398 & 2.384 & 1.755 & 0.822 & 0.97 & 1.359 & $0.177 * *$ \\
\hline$N$ & 208 & 418 & 516 & 548 & 603 & 727 & 567 & 615 & 329 & 757 & 407 \\
\hline
\end{tabular}

Bold values reflect odd ratios that are significant at least at 5\% level, i.e. $p<0.05$

Odds ratios reported in the table; ${ }^{*} p<0.10,{ }^{* *} p<0.05$, ${ }^{* * *} p<0.01$

Southern and Eastern European countries, on the contrary, are characterized by low levels of welfare provisions and a strong reliance on the family as a locus of support (Trifiletti 1999). These countries tend to have lower fertility rates, a higher mean age at childbearing, stronger gender norms, and greater levels of intergenerational transfers that can influence social support and health outcomes in older ages. The results of the present study cannot be fully explained through this theoretical model or by the national differences in gender equality at the institutional and household levels (McDonald 2000a), as some of the cross-national differences contradict the hypothesized outcomes. It is important to note that the low significance of some of the associations found in the analyses may be due to small sample sizes. More research is needed to explain cross-national findings, possibly using larger samples.

Population ageing is one of the most important demographic phenomena taking place in developed countries. This study shows that it is important to consider life course events, such as childbearing, in order to understand health outcomes at older ages and to investigate the cumulative effects that can lead to healthier or unhealthier ageing processes.

This study is not without limitations. The sample size for each country is small, especially when the analysis was stratified by gender and when the age at childbearing, birth intervals, and death of a child were analysed. Therefore, the power of the analysis might be limited. Moreover, the measure of chronic disease as diagnosed by a doctor is only partially objective, as it reflects such diagnoses through self-reports; this measure would be more reliable if a doctor or a nurse reported the response. That might be why the results do not show large differences in the relationship between fertility and chronic diseases across the two measures. However, it is important to compare different measures for chronic conditions, given the fact that the previous literature has found mixed findings depending on the measure used. Finally, as not all European countries were included 
in the sample the results cannot be generalized to Europe as a whole without some caution.

Future research should focus more on cross-national comparisons because there are differences across countries that cannot be entirely accounted for by welfare system theory, possibly looking at historical and cultural explanations. Additionally, different measures of health should be used, comparing self-reported measures with objective measures such as biomarkers and diagnoses based on health examinations performed by doctors. Moreover, given the interconnectedness of the fertility aspects considered here, it would be useful to examine fertility trajectories as a whole, while also taking partnership histories into account.

\section{Conclusions}

The results of the present study are useful to identify groups in the population that are more at risk of developing chronic conditions and unhealthy ageing. In particular, findings show the importance of age at first birth among women; having a teenage pregnancy or having the first child after age 35 is associated with an increased risk of chronic conditions later in life. These recognized groups may benefit from tailored interventions or more health monitoring, in order to prevent future health complications. This is increasingly important, given current trends of fertility decline and increase in the age at childbearing, and given the phenomenon of population ageing that is taking place across Europe.

Acknowledgements The work reported here was supported and funded by the British Academy, as part of the project "Is Having Children Detrimental to Your Health? A Cross-national Investigation of Fertility Trajectories and Health in Later Life" (\# 169934). The author also thanks Julie Fricke for the useful comments and feedback, and Hannaliis Jaadla for her help with data analysis.

\section{Compliance with ethical standards}

Conflict of interest The author declares not to have any conflict of interest.

Open Access This article is distributed under the terms of the Creative Commons Attribution 4.0 International License (http://creativeco mmons.org/licenses/by/4.0/), which permits unrestricted use, distribution, and reproduction in any medium, provided you give appropriate credit to the original author(s) and the source, provide a link to the Creative Commons license, and indicate if changes were made.

\section{References}

Barker DJP (1997) Maternal nutrition, fetal nutrition, and disease in later life. Nutrition 13:807-813. https://doi.org/10.1016/S0899 -9007(97)00193-7
Barker DJP (2004) Developmental origins of adult health and disease. J Epidemiol Community Health. https://doi.org/10.1136/ jech.58.2.114

Barker DJP, Eriksson JG, Forsen T, Osmond C (2002) Fetal origins of adult disease: strength of effects and biological basis. Int $\mathrm{J}$ Epidemiol 31:1235-1239

Börsch-Supan A (2018) Survey of health, ageing and retirement in Europe (SHARE) wave 5. Release version: 6.1.1. SHARE-ERIC Data set 5

Börsch-Supan A, Jürges H (2005) The survey of health, ageing and retirement in Europe-methodology

Buber I, Engelhardt H (2008) Children's impact on the mental health of their older mothers and fathers: findings from the survey of health, ageing and retirement in Europe. Eur J Ageing 5:31-45. https:// doi.org/10.1007/s10433-008-0074-8

Campbell F, Conti G, Heckman JJ et al (2014) Early childhood investments substantially boost adult health. Science (New York, NY) 343:1478-1485. https://doi.org/10.1126/science.1248429

Case A, Fertig A, Paxson C (2005) The lasting impact of childhood health and circumstance. J Health Econ 24:365-389

Clark G, Cummins N (2009) Urbanization, mortality, and fertility in Malthusian England. Am Econ Rev. https://doi.org/10.1257/ aer.99.2.242

Clark G, Hamilton G (2006) Survival of the richest: the Malthusian mechanism in pre-industrial England. J Econ Hist 66:30. https ://doi.org/10.1017/S0022050706000301

Cohen S, Janicki-Deverts D, Chen E, Matthews KA (2010) Childhood socioeconomic status and adult health. Ann N Y Acad Sci 1186:37-55

Dior UP, Hochner H, Friedlander Y et al (2013) Association between number of children and mortality of mothers: results of a 37-year follow-up study. Ann Epidemiol 23:13-18. https://doi. org/10.1016/j.annepidem.2012.10.005

Doblhammer G (2000) Reproductive history and mortality later in life: a comparative study of England and Wales and Austria. Popul Stud 54:169-176. https://doi.org/10.1080/713779087

Dribe M, Oris M, Pozzi L (2014) Socioeconomic status and fertility before, during, and after the demographic transition: an introduction. Demogr Res 31:161-182. https://doi.org/10.4054/ DemRes.2014.31.7

Duncan GJ, Ziol-Guest KM, Kalil A (2010) Early-childhood poverty and adult attainment, behavior, and health. Child Dev 81(1):306-325

Engelman M, Agree EM, Yount KM, Bishai D (2010) Parity and parents' health in later life: the gendered case of Ismailia, Egypt. Popul Stud 64:165-178. https://doi.org/10.1080/0032472100 3660511

Esping-Andersen G (2013) The three worlds of welfare capitalism. Wiley, Cambridge

Esping-Andersen G, Billari FC (2015) Re-theorizing family demographics. Popul Dev Rev 41:1-31. https://doi.org/10.111 1/j.1728-4457.2015.00024.x

European Commission (2014) Population ageing in Europe-Facts, implications and policies

Eurostat (2016) Causes of death statistics

Falci CD, Mortimer JT, Noel H (2010) Parental timing and depressive symptoms in early adulthood. Adv Life Course Res 15:1-10

Goisis A, Sigle-Rushton W (2014) Childbearing postponement and child well-being: a complex and varied relationship? Demography 51:1821-1841. https://doi.org/10.1007/s13524-014-0335-4

Grundy E (2009) Women's fertility and mortality in late mid life: a comparison of three contemporary populations. Am J Hum Biol 21:541-547. https://doi.org/10.1002/ajhb.20953

Grundy E, Foverskov E (2016) Age at first birth and later life health in Western and Eastern Europe. Popul Dev Rev 42:245-269 
Grundy E, Holt G (2000) Adult life experiences and health in early old age in Great Britain. Soc Sci Med 51:1061-1074

Grundy E, Kravdal Ø (2007) Reproductive history and mortality in late middle age among Norwegian men and women. Am J Epidemiol 167:271-279. https://doi.org/10.1093/aje/kwm295

Grundy E, Kravdal Ø (2010) Fertility history and cause-specific mortality: a register-based analysis of complete cohorts of Norwegian women and men. Soc Sci Med 70:1847-1857

Grundy E, Read S (2015) Pathways from fertility history to later life health: results from analyses of the English longitudinal study of ageing. Demogr Res 32:107-146. https://doi.org/10.4054/DemRe s.2015.32.4

Grundy E, Tomassini C (2005) Fertility history and health in later life: a record linkage study in England and Wales. Soc Sci Med 61:217-228

Grundy E, Tomassini C (2006) Fatherhood history and later life health and mortality in England and Wales: a record linkage study. Soc Biol 53:189-205. https://doi.org/10.1080/19485565.2006.99891 26

Gunes PM (2016) The effects of teenage childbearing on long-term health in the US: a twin-fixed-effects approach. Econ Househ. https://doi.org/10.1007/s11150-016-9326-0

Halfon N, Hochstein M (2002) Life course health development: an integrated framework for developing health, policy, and research. Milbank Q

Hank K (2010) Childbearing history, later-life health, and mortality in Germany. Popul Stud 63:275-291. https://doi.org/10.1080/00324 728.2010.506243

Hanson HA, Smith KR, Zimmer Z (2015) Reproductive history and later-life comorbidity trajectories: a medicare-linked cohort study from the utah population database. Demography 52:2021-2049. https://doi.org/10.1007/s13524-015-0439-5

Hardy R, Lawlor DA, Black S et al (2007) Number of children and coronary heart disease risk factors in men and women from a British birth cohort. BJOG 114:721-730. https://doi.org/10.111 1/j.1471-0528.2007.01324.x

Heinig MJ, Dewey KG (1997) Health effects of breast feeding for mothers: a critical review. Nutr Res Rev 10:35-56. https://doi. org/10.1079/NRR19970004

Henretta JC (2007) Early childbearing, marital status, and women's health and mortality after age 50. J Health Soc Behav 48:254-266

Henretta JC, Grundy EMD, Okell LC, Wadsworth MEJ (2008) Early motherhood and mental health in midlife: a study of British and American cohorts. Aging Ment Health 12:605-614. https://doi. org/10.1080/13607860802343084

Hinkula M, Kauppila A, Nayha S, Pukkala E (2005) Original contribution cause-specific mortality of grand multiparous women in Finland. Am J Epidemiol 163:367-373. https://doi.org/10.1093/ aje/kwj048

Huisman M, Kunst AE, Mackenbach JP (2003) Socioeconomic inequalities in morbidity among the elderly: a European overview. Soc Sci Med

Hurt LS, Ronsmans C, Thomas SL (2006) The effect of number of births on women's mortality: systematic review of the evidence for women who have completed their childbearing. Popul Stud 60:55-71. https://doi.org/10.1080/00324720500436011

Jaffe DH, Neumark YD, Eisenbach Z, Manor O (2009) Parityrelated mortality: shape of association among middle-aged and elderly men and women. Eur J Epidemiol 24:9-16. https://doi. org/10.1007/s10654-008-9310-y

Jaffe DH, Eisenbach Z, Manor O (2011) The effect of parity on causespecific mortality among married men and women. Matern Child Health J 15:376-385. https://doi.org/10.1007/s10995-010-0591-x

Kravdal Ø, Grundy E, Lyngstad TH, Wiik KA (2012) Family life history and late mid-life mortality in Norway. Popul Dev Rev 38:237-257
Kuh D, Shlomo YB (2004) A life course approach to chronic disease epidemiology. Oxford University Press, Oxford

Kuh D, Cooper R, Hardy R et al (2013) A life course approach to healthy ageing. OUP, Oxford

Lacey RE, Sacker A, Kumari M et al (2016) Work-family life courses and markers of stress and inflammation in mid-life: evidence from the National Child Development Study. Int J Epidemiol 45:12471259. https://doi.org/10.1093/ije/dyv205

Malter F, Börsch-Supan A (2015) SHARE wave 5: innovations \& methodology. MEA, Max Planck Institute for Social Law and Social Policy, Munich

Marmot M (2005) Social determinants of health inequalities. Lancet. https://doi.org/10.1016/s0140-6736(05)74234-3

McDonald P (2000a) Gender equity in theories of fertility transition. Popul Dev Rev 26:427-439

McDonald P (2000b) Gender equity, social institutions and the future of fertility. J Popul Res 17:1-16. https://doi.org/10.1007/BF030 29445

McDonald P (2006) Low fertility and the state: the efficacy of policy. Popul Dev Rev 32:485-510. https://doi.org/10.111 1/j.1728-4457.2006.00134.x

O'Flaherty M, Baxter J, Haynes M, Turrell G (2016) The family life course and health: partnership, fertility histories, and later-life physical health trajectories in Australia. Demography 53:1-28. https://doi.org/10.1007/s13524-016-0478-6

O'Leary L, Natamba E, Jefferies J, Wilson B (2010) Fertility and partnership status in the last two decades. Popul Trends. https://doi. org/10.1057/pt.2010.10

Pirkle CM, Sousa ACPA, Alvarado B, Zunzunegui M-V (2014) Early maternal age at first birth is associated with chronic diseases and poor physical performance in older age: cross-sectional analysis from the International Mobility in Aging Study. BMC Public Health 14:1-13

Read S, Grundy E (2011) Mental health among older married couples: the role of gender and family life. Soc Psychiatry Psychiatr Epidemiol 46:331-341. https://doi.org/10.1007/s00127-010-0205-3

Read S, Grundy E, Wolf DA (2011) Fertility history, health, and health changes in later life: a panel study of British women and men born 1923-1949. Popul Stud 65:201-215. https://doi. org/10.1080/00324728.2011.572654

Roseboom T, Van der Meulen J, Ravelli A et al (2001) Effects of prenatal exposure to the Dutch famine on adult disease in later life: an overview. Mol Cell Endocrinol 185:93-98

Skirbekk V (2008) Fertility trends by social status. Demogr Res 18:145-180. https://doi.org/10.4054/DemRes.2008.18.5

Spence NJ (2008) The long-term consequences physical and psychological well-being of mothers in later life. Res Aging 30:722-751

Spence NJ, Eberstein IW (2009) Age at first birth, parity, and postreproductive mortality among white and black women in the US, 1982-2002. Soc Sci Med 68:1625-1632. https://doi.org/10.1016/j. socscimed.2009.02.018

Tamakoshi A, Tamakoshi K, Lin Y et al (2010) Number of children and all-cause mortality risk: results from the Japan Collaborative Cohort Study. Eur J Pub Health 21:732-737. https://doi. org/10.1093/eurpub/ckq175

Trifiletti R (1999) Southern European welfare regimes and the worsening position of women. J Eur Soc Policy 9:49-64. https://doi. org/10.1177/095892879900900103

Williams K, Sassler S, Frech A et al (2011) Nonmarital childbearing, union history, and women's health at midlife. Am Sociol Rev 76:465-486. https://doi.org/10.1177/0003122411409705 